\title{
O ESPAÇO COMO PALAVRA-CHAVE ${ }^{1}$
}

\author{
DAVID HARVEY \\ Universidade de Nova York
}

Se Raymond Williams retomasse hoje a lista das entradas de seu célebre livro sobre Keywords (palavras-chave) ${ }^{2}$, ele certamente incluiria a palavra "espaço". Ele poderia muito bem incluí-la na curta lista de conceitos que, como "cultura" e "natureza", estão "entre as palavras mais complicadas da nossa língua" (WILLIAMS, 1985). Como, então, podemos decifrar o espectro de significações dadas à palavra "espaço" sem nos perdermos em um labirinto (metáfora espacial interessante) de complicações?

A palavra "espaço" suscita, frequentemente, modificações. Complicações às vezes surgem dessas modificações (muito frequentemente omitidas na fala ou na escrita), mais do que de uma complexidade inerente à própria noção de espaço. Quando, por exemplo, referimo-nos ao espaço "material", "metafórico", "liminar", "pessoal", "social" ou "psíquico" (usando somente alguns exemplos), indicamos uma variedade de contextos que, assim, contribuem para construir o significado de espaço contingente segundo esses contextos. De forma similar, quando construímos expressões como espaços do medo, do jogo, da cosmologia, dos sonhos, da raiva, da física das partículas, do capital, da tensão geopolítica, de esperança, da memória ou da interação ecológica (mais uma vez, somente para indicar alguns dos desdobramentos aparentemente infinitos do termo), os domínios de aplicação são tão particulares que tornam impossível qualquer definição genérica de espaço. Dentro do que se segue, contudo, irei deixar de lado

${ }^{1}$ Original: Harvey, D. 2006. Space as a keyword. In: Castree, N. e Gregory, D. (org.) David Harvey: a critical reader. Malden e Oxford: Blackwell. Tradução livre: Letícia Gianella. Revisão técnica: Rogério Haesbaert e Juliana Nunes. Dada a formatação de nossa revista, optamos por incorporar a divisão em tópicos presente na tradução francesa (HARVEY, D. 2010. Géographie et Capital: vers um matérialisme históricogéographique. Paris: Syllepse).

${ }^{2}$ David Harvey se refere aqui ao livro "Palavras-Chave", de Raymond Williams, publicado em português em 2007 pela Editora Boitempo (São Paulo). (N.R.) 
essas dificuldades e arriscar uma decifração genérica do significado do termo. Espero, assim, dispersar um pouco a névoa da falta de comunicação que parece atormentar o uso da palavra.

O ponto de partida que escolhemos para esta investigação não é inocente, todavia, já que ele inevitavelmente define uma perspectiva particular que destaca alguns tópicos enquanto encobre outros. Certo privilégio, naturalmente, é concedido à reflexão filosófica, uma vez que a filosofia aspira estar acima dos vários e divergentes campos das práticas humanas e dos conhecimentos parciais, a fim de atribuir significados definitivos às categorias às quais podemos recorrer. Parece-me que há suficiente dissenso e confusão entre os filósofos quanto ao significado de espaço para que ele possa constituir um ponto de partida não problemático. Além disso, já que não sou de modo algum qualificado para refletir sobre o conceito de espaço a partir do interior da tradição filosófica, parece preferível começar do ponto que conheço melhor. Por isso parto do ponto de vista do geógrafo, não porque este seja um ponto de vista privilegiado que de algum modo disporia de um direito de propriedade (como alguns geógrafos às vezes parecem reivindicar) sobre o uso dos conceitos espaciais, mas porque é aí que se passa a maior parte do meu trabalho. É nesta arena que me deparei mais diretamente com a complexidade que envolve o significado da palavra "espaço". Tenho, obviamente, com frequência, inspirado-me no trabalho de autores que operam em vários campos da divisão acadêmica e intelectual do trabalho, bem como no trabalho de muitos geógrafos (demasiados para serem reconhecidos em um breve ensaio como este) que, ao seu modo, têm se engajado ativamente na exploração desses problemas. Não tentarei fazer aqui nenhuma síntese de todo esse trabalho. Farei uma colocação puramente pessoal de como meus pontos de vista têm evoluído (ou não) conforme busco significações operatórias, tão satisfatórias quanto possível, em relação às temáticas teóricas e práticas que constituíram minhas preocupações básicas.

\section{O espaço: absoluto, relativo e relacional}

Comecei a refletir sobre este problema há muitos anos. Em Social Justice and the City, publicado em $1973^{3}$, argumentei que era crucial refletir sobre a natureza do espaço se estávamos buscando entender os

\footnotetext{
3 “A justiça social e a cidade”, editado no Brasil pela editora Hucitec (São Paulo, 1980). (N.R.)
} 
processos urbanos sob o capitalismo. Trabalhando sobre ideias previamente selecionadas de um estudo de filosofia da ciência e parcialmente exploradas em Explanation in Geography, identifiquei uma divisão tripartite no modo como o espaço poderia ser entendido:

Se considerarmos o espaço como absoluto ele se torna uma "coisa em si mesma", com uma existência independente da matéria. Ele possui então uma estrutura que podemos usar para classificar ou distinguir fenômenos. A concepção de espaço relativo propõe que ele seja compreendido como uma relação entre objetos que existe pelo próprio fato dos objetos existirem e se relacionarem. Existe outro sentido em que o espaço pode ser concebido como relativo e eu proponho chamá-lo espaço relacional - espaço considerado, à maneira de Leibniz, como estando contido em objetos, no sentido de que um objeto pode ser considerado como existindo somente na medida em que contém e representa em si mesmo as relações com outros objetos (HARVEY, 1973:13).

Considero que esta divisão tripartite é bem sustentada. Assim, começarei com uma breve elaboração sobre o que cada uma dessas categorias pode implicar.

Espaço absoluto é fixo e nós registramos ou planejamos eventos dentro da moldura que o constitui. Este é o espaço de Newton e Descartes e é usualmente representado como uma grade pré-existente e imóvel que permite padronizar medições e está aberto ao cálculo. Geometricamente é o espaço de Euclides e, portanto, o espaço de todas as formas de mapeamento cadastral e práticas de engenharia. É o espaço primário de individuação - a res extensa, como afirma Descartes - e refere-se a todos os fenômenos discretos e delimitados, e do qual você e eu fazemos parte enquanto pessoas individuais. Socialmente, é o espaço da propriedade privada e de outras entidades territoriais delimitadas (como Estados, unidades administrativas, planos urbanos e grades urbanas). Quando o engenheiro de Descartes contempla o mundo com um sentido de domínio, trata-se de um mundo de espaço (e de tempo) absoluto onde todas as incertezas e ambiguidades podem em princípio ser banidas e onde o cálculo humano pode florescer sem entraves.

A noção de espaço relativo é associada principalmente ao nome de Einstein e às geometrias não-euclidianas que começaram a ser mais sistematicamente construídas no século XIX. O espaço é relativo em dois 
sentidos: de que há múltiplas geometrias que podemos escolher e de que o quadro espacial depende estritamente daquilo que está sendo relativizado e por quem. Quando Gauss estabeleceu pela primeira vez as regras da geometria esférica não-euclidiana para lidar com os problemas da descrição precisa da superfície curva da Terra, ele também afirmou a declaração de Euler de que um mapa com escala perfeita de qualquer porção da superfície terrestre é impossível. Einstein tomou o argumento mais tarde pontuando que todas as formas de medição dependem do modelo de referência do observador. A ideia da simultaneidade no universo físico, ele disse, deve ser abandonada. Deste ponto de vista, é impossível compreender o espaço independentemente do tempo, e isto implica uma modificação importante na linguagem, com uma passagem do espaço e do tempo ao espaço-tempo ou espaço-temporalidade. Isto foi, claro, a realização de Einstein para chegar com termos exatos para examinar fenômenos como a curvatura do espaço, ao examinar processos temporais operando na velocidade da luz (OSSERMAN, 1995). Mas no esquema de Einstein o tempo permanece fixo enquanto é o espaço que dobra de acordo com certas regras observáveis (da mesma maneira que Gauss elabora a geometria esférica como um modo de investigar através da triangulação a superfície curva da Terra). Em um nível bem trivial da atividade do geógrafo, nós sabemos que o espaço das relações parece ser, e é, muito diferente dos espaços da propriedade privada. $\mathrm{O}$ caráter único da localização e da individualização, definido pelos territórios limitados do espaço absoluto, oferece um caminho para uma multiplicidade de localizações que são equidistantes de, digamos, alguma localização central da cidade. Podemos criar mapas completamente diferentes de localizações relativas diferenciando-as entre distâncias medidas em termos de custo, tempo, modo de transporte (carro, bicicleta ou skate) e mesmo interromper continuidades espaciais ao olhar para redes, relações topológicas (a rota ótima para o carteiro), e assim por diante. Sabemos, dadas as fricções diferenciais da distância encontradas na superfície terrestre, que a distância mais curta (medida em termos de tempo, custo, energia gastos) entre dois pontos não é necessariamente dada pela linha reta frequentemente imaginada. Ademais, o ponto de vista do observador joga um papel crucial. A típica visão de New York no mundo, como o famoso cartoon de Steinberg sugere, desaparece rapidamente quando pensamos nas terras do oeste do rio Hudson ou do leste de Long Island. Toda esta relativização, é importante notar, não necessariamente reduz ou elimina a capacidade de cálculo ou controle, mas ela indica que regras e leis especiais são necessárias para fenômenos particulares e processos em consideração. 
Dificuldades aparecem, contudo, se ambicionamos integrar conhecimentos de diferentes campos em um esforço mais unificado. A espaçotemporalidade necessária para representar fluxos de energia através de sistemas ecológicos adequadamente, por exemplo, pode não ser compatível com aquela de fluxos financeiros através de mercados globais. Entender os ritmos espaço-temporais da acumulação de capital requer um quadro bastante diferente daquele necessário para entender as mudanças climáticas globais. Tais disjunções, que tornam o trabalho extremamente difícil, não são necessariamente uma desvantagem desde que as reconheçamos como tais. Comparações entre molduras espaço-temporais diferentes podem iluminar os problemas da escolha política. (Devemos favorecer a espaçotemporalidade dos fluxos financeiros ou aquela dos processos ecológicos que eles tipicamente destroem, por exemplo?).

O conceito relacional de espaço é mais frequentemente associado ao nome de Leibniz que, em uma famosa série de cartas a Clarke (efetivamente uma relação próxima de Newton), faz sérias objeções à visão absoluta do espaço e tempo tão central às teorias de Newton. Sua principal objeção é teológica. Newton dava a entender que até mesmo Deus estava dentro do espaço e do tempo absolutos mais do que no comando da espaço-temporalidade. Por extensão, a visão relacional do espaço sustenta que não há tais coisas como espaço ou tempo fora dos processos que os definem. (Se Deus faz o mundo então Ele também escolheu fazer, fora de muitas possibilidades, espaço e tempo de um tipo particular). Processos não ocorrem no espaço mas definem seu próprio quadro espacial. $\mathrm{O}$ conceito de espaço está embutido ou é interno ao processo. Esta formulação implica que, como no caso do espaço relativo, é impossível separar espaço e tempo. Devemos, portanto, focar no caráter relacional do espaço-tempo mais do que no espaço isoladamente. A noção relacional do espaço-tempo implica a ideia de relações internas; influências externas são internalizadas em processos ou coisas específicos através do tempo (do mesmo modo que minha mente absorve todo tipo de informação e estímulos externos para dar lugar a padrões estranhos de pensamento, incluindo tanto sonhos e fantasias quanto tentativas de cálculo racional). Um evento ou uma coisa situada em um ponto no espaço não pode ser compreendido em referência apenas ao que existe somente naquele ponto. Ele depende de tudo o que acontece ao redor dele (do mesmo modo que todos aqueles que entram em uma sala para discutir trazem com eles um vasto espectro de dados da experiência acumulados na sua relação com o mundo. Uma grande variedade de influências diferentes que turbilham sobre o espaço no passado, no presente e no futuro concentram e congelam 
em um certo ponto (por exemplo, em uma sala de conferência) para definir a natureza daquele ponto. A identidade, nesta argumentação, significa algo bastante diferente do sentido que temos dela a partir do espaço absoluto. Assim chegamos a uma versão ampliada do conceito de mônada de Leibniz.

Medições se tornam mais e mais problemáticas quando nos movemos em direção a um mundo de espaço-tempo relacional. Mas por que seria presumível que o espaço-tempo somente existe se é mesurável e quantificável em certas formas tradicionais? Isto nos leva a algumas reflexões interessantes sobre o fracasso (talvez seja melhor falarmos de simples limitações) do positivismo e empirismo para desenvolver abordagens adequadas dos conceitos espaço-temporais para além daqueles que podem ser mensurados. De certo modo, concepções relacionais de espaço-tempo nos levam ao ponto onde matemática, poesia e música convergem, se não mesmo se fundem. E isto, de um ponto de vista científico (em oposição ao estético), é um anátema para aqueles de inclinação positivista ou materialista vulgar. Neste ponto, o compromisso kantiano de reconhecer o espaço como real mas somente acessível pela intuição tenta construir uma ponte entre Newton e Leibniz precisamente pela incorporação do conceito de espaço à teoria do juízo estético. Contudo, o retorno à popularidade e importância de Leibniz, não somente como o guru do ciberespaço mas também como um dos pensadores fundamentais para abordagens mais dialéticas do problema da relação cérebro-mente e das formulações da teoria quântica, sinaliza algum tipo de impulso para além dos conceitos absolutos e relativos e de suas qualidades mais facilmente mensuráveis, bem como do compromisso kantiano. Mas o terreno relacional é um terreno extremamente desafiador e difícil para se trabalhar. Há muitos pensadores que, com o passar dos anos, aplicaram seu talento para refletir sobre o pensamento relacional. Alfred North Whitehead era fascinado pela necessidade da abordagem relacional e contribuiu muito para o seu avanço ${ }^{4}$. Deleuze também desenvolveu muitas dessas ideias tanto em suas reflexões sobre Leibniz (com as reflexões sobre a arquitetura barroca e os matemáticos da dobra no trabalho de Leibniz), quanto naquelas sobre Spinoza.

\footnotetext{
${ }^{4}$ Fitzgerald (1979); tentei chegar a um acordo com as abordagens de Whitehead em Harvey (1996)
} 


\section{Usos dos modos espaço-temporais}

Mas por que e como eu poderia, como um geógrafo em atividade, considerar útil o modo de abordagem relacional do espaço-tempo? A resposta é simplesmente que certas temáticas, como o papel político das memórias coletivas nos processos urbanos, somente podem ser abordadas desta maneira. Não posso encerrar as memórias políticas e coletivas dentro de um espaço absoluto (situá-las claramente em uma grade ou sobre um mapa), nem compreender sua circulação em função de regras, ainda que sofisticadas, do espaço-tempo relativo. Se coloco a questão: "o que significa a praça Tiananmen ou Ground Zero [Marco Zero] ${ }^{5}$ ?", o único modo de encontrar uma resposta é pensando em termos relacionais. Este é o problema com o qual me confrontei quando escrevia sobre a basílica de Sacré-Coeur de Paris. Também, como mostrarei em breve, é impossível compreender a economia politica marxista sem adotar uma perspectiva relacional.

Assim, o espaço (espaço-tempo) é absoluto, relativo ou relacional? Não sei se existe uma resposta ontológica a esta questão. No meu trabalho, considero o espaço como sendo os três. Esta foi a conclusão a que cheguei há trinta anos e não encontrei nenhuma razão particular para mudar de opinião. Veja o que escrevi à época:

O espaço não é nem absoluto, nem relativo, nem relacional em si mesmo, mas ele pode tornar-se um ou outro separadamente ou simultaneamente em função das circunstâncias. O problema da concepção correta do espaço é resolvido pela prática humana em relação a ele. Em outros termos, não há respostas filosóficas a questões filosóficas que concernem à natureza do espaço - as respostas se situam na prática humana. A questão “o que é o espaço?" é por consequência substituída pela questão "como é que diferentes práticas humanas criam e usam diferentes concepções de espaço?". A relação de propriedade, por exemplo, cria espaços absolutos nos quais o controle monopolista pode operar. O movimento de pessoas, de bens, serviços e informação realiza-se no espaço relativo porque o dinheiro, tempo, energia, etc, são necessários para superar a fricção da distância. Parcelas de terra também incorporam benefícios

\footnotetext{
5 "Marco Zero" é o local onde se encontravam as Torres Gêmeas em Manhattan, Nova York. (N.R.)
} 
porque contêm relações com outras parcelas... sob a forma do arrendamento, o espaço relacional se torna um aspecto importante da prática social humana (Harvey, 1973).

Há regras para decidir onde e quando um quadro espacial é preferível a outro? Ou a escolha é arbitrária, sujeita aos caprichos da prática humana? A decisão de utilizar uma ou outra concepção depende certamente da natureza dos fenômenos considerados. A concepção absoluta pode ser perfeitamente adequada para as questões de delimitação da propriedade e determinação de fronteiras, mas ela não auxilia em nada na questão sobre o que é a praça Tiananmen, Ground Zero [Marco Zero] ou a basílica do Sacré-Coeur. Por isso considero útil - ao menos a título de teste interno - esboçar justificativas pela escolha de um espaço de referência absoluto, relativo ou relacional. Além disso, muitas vezes em minhas práticas me vejo presumindo que há alguma hierarquia no trabalho entre esses três espaços no sentido de que o espaço relacional pode incluir os espaços relativo e absoluto, o relativo pode incluir o espaço absoluto, mas que o espaço absoluto é apenas absoluto. Mas, sem hesitação, não avançarei neste ponto de vista como um princípio heurístico e, mais ainda, não tentarei defendê-lo teoricamente. Acho mais interessante conservar os três conceitos em tensão dialética um com o outro e pensar constantemente nas interações que eles travam entre si. Ground Zero [Marco Zero] é um espaço absoluto ao mesmo tempo em que é relativo e relacional no espaçotempo. Deixe-me tentar colocar essas ideias em um contexto imediato. Eu faço uma conferência em uma sala. O alcance das minhas palavras é limitado pelo espaço absoluto de suas paredes particulares, e pelo tempo absoluto da conferência. Para me ouvir, as pessoas devem estar presentes no interior deste espaço absoluto e durante este tempo absoluto. As pessoas que não podem entrar na sala são excluídas e aquelas que chegam mais tarde não poderão me ouvir. Aquelas que estão presentes podem ser identificadas como indivíduos - individualizados - cada um em função de um espaço absoluto, como, por exemplo, o assento que ele ocupa durante este período de tempo. Mas me encontro igualmente em um espaço relativo em relação ao meu público. Estou aqui e ele está lá. Tento me comunicar através do espaço por um meio - a atmosfera - que refrata minhas palavras de modo diferenciado. Eu falo com voz baixa e a clareza das minhas palavras se desvanece através do espaço: a última fileira não escuta mais nada. Se há uma difusão da conferência por vídeo em Aberdeen, eu posso ser escutado lá mas não na última fileira da própria sala. Minhas palavras são recebidas de maneira diferenciada no espaço-tempo relativo. A individualização é mais problemática uma vez que são muitas pessoas 
exatamente na mesma localização relativa que eu neste espaço-tempo. Todas as pessoas que se encontram na primeira fileira são equidistantes em relação a mim. Uma descontinuidade no espaço-tempo surge entre aqueles que podem ouvir e aqueles que não podem. A análise do que está acontecendo no espaço e tempo absolutos da conferência na sala parece muito diferente quando analisada através da lente do espaço-tempo relativo. Mas então há ainda o componente relacional. Indivíduos na audiência trazem ao espaço e tempo absolutos da conferência todo tipo de ideias e experiências adquiridas a partir do espaço-tempo de suas próprias trajetórias de vida e tudo isto está co-presente na sala: ele não pode parar de pensar no debate que houve durante o café da manhã, ela não pode apagar de sua mente as terríveis imagens de morte e destruição que viu nas notícias da noite anterior. Qualquer coisa na minha maneira de falar lembra a cada uma dessas pessoas presentes um evento traumático perdido em um passado distante, e minhas palavras fazem lembrar uma outra reunião política que ela frequentava nos anos 1970. Minhas palavras expressam certa raiva sobre o que está acontecendo no mundo. Percebo-me pensando enquanto falo que tudo o que estamos fazendo nesta sala é estúpido e trivial. Há uma tensão palpável na sala. Por que não tentamos derrubar o governo? Eu me liberto de todas essas relacionalidades, me volto ao espaço absoluto e relativo da sala e tento abordar o tema do espaço como palavrachave de maneira seca e técnica. A tensão se dissipa e alguém na primeira fila cochila. Eu sei onde todo mundo se encontra no espaço e tempo absolutos, mas não faço a menor ideia, como diz o ditado, de "onde se encontra a cabeça das pessoas". Posso suspeitar que certas pessoas seguem minhas palavras e outras não, mas nunca estou seguro. Eis aí, contudo, seguramente, o elemento mais importante disso tudo. É aqui, sobretudo, que consiste a transformação das subjetividades políticas. A relacionalidade é enganosa, se não mesmo impossível de apreender, mas nem por isso é menos essencial.

Com esse exemplo, espero mostrar que existe um limiar a respeito da própria espacialidade, porque nós nos situamos inevitavelmente dentro dos três quadros de referência simultaneamente, ainda que não necessariamente de maneira equivalente. Podemos acabar, muitas vezes sem notar, favorecendo uma ou outra definição através de nossas ações. Em um modo absoluto, vou realizar uma ação e tentar chegar a um conjunto de conclusões; em um modo relativo, construirei minhas interpretações diferentemente e farei algo a mais; e se tudo parece ser diferente através dos filtros relacionais, me conduzirei de um modo muito diferente. Aquilo que nós fazemos, tanto quanto o que compreendemos, é 
integralmente dependente do quadro espaço-temporal primário dentro do qual nós nos situamos. Consideremos a maneira como isto funciona examinando o mais perigoso dos conceitos sociopolíticos, a saber, o conceito de "identidade". As escolhas são claras no espaço e tempo absolutos, mas elas se tornam mais fluidas quando passamos ao espaçotempo relativo, e muito difíceis em um mundo relacional. Mas é somente dentro deste último quadro que nós podemos nos confrontar com numerosos aspectos da política contemporânea, na medida em que se trata de um mundo de subjetividade e de consciências políticas. Du Bois tentou, há muito tempo, formular o problema em termos do que ele chamou de "dupla consciência" - o que significa, ele perguntou, carregar em si mesmo a experiência de ser tanto negro quanto americano? Podemos complicar ainda mais a questão perguntando o que significa ser americana, negra, mulher, lésbica e da classe trabalhadora? Como todas essas relacionalidades entram na consciência política do sujeito? E quando consideramos outras dimensões - de migrantes, grupos de diásporas, turistas e viajantes e aqueles que assistem à atual mídia global e parcialmente filtram ou absorvem suas mensagens cacofônicas - então a questão primária com que estamos lidando é entender como todo este mundo relacional de experiência e informação se internaliza no sujeito político particular (ainda que individualizado no espaço e tempo absolutos) para suportar esta ou aquela linha de pensamento e de ação. Claramente, não podemos compreender o terreno mutável no qual subjetividades políticas se formam e ações políticas ocorrem sem pensar sobre o que acontece em termos relacionais.

Se a distinção entre as concepções absoluta, relativa e relacional do espaço fosse o único meio para desvendar o significado de espaço como palavra-chave, poderíamos permanecer aí. Feliz ou infelizmente, há outros modos igualmente convincentes de tratar este problema. Muitos geógrafos, por exemplo, recentemente sinalizaram uma importante diferença entre o uso do conceito de espaço como elemento essencial dentro de um projeto materialista de compreensão de geografias concretas sobre o terreno e o emprego geral de metáforas espaciais na teoria social, literária e cultural. Estas metáforas, além disso, foram frequentemente utilizadas para submeter à crítica as metanarrativas (como a teoria marxiana) e as estratégias discursivas nas quais a dimensão temporal predomina. Isso provocou um imenso debate sobre o papel do espaço na teoria social, literária e cultural. Não tenho a intenção de entrar nos detalhes da discussão sobre o que chamamos a "virada espacial" em geral, nem sobre sua relação com o pós-modernismo em particular. Mas minha própria 
posição sempre foi bem clara: a própria consideração do espaço e do espaço-tempo tem efeitos cruciais sobre como teorias e abordagens são articuladas e desenvolvidas. Isto não justifica, porém, absolutamente renunciar a toda tentativa de formulação de metateorias (a consequência seria nos fazer retornar à geografia dos anos 1950 - que é, de forma interessante, a tendência, ainda que inconsciente, de um significativo segmento da geografia britânica atual). Considerar o espaço como uma palavra-chave consiste, neste sentido, em compreender a maneira pela qual o conceito pode ser vantajosamente integrado dentro das metateorias sociais, literárias e culturais existentes, e examinar os efeitos.

Cassirer, por exemplo, elabora uma divisão tripartite dos modos humanos da experiência espacial ao distinguir entre os espaços orgânico, perceptivo e simbólico (CASSIRER, 1944; ver tb. Harvey, 1973:28). O primeiro designa todas as formas de experiências espaciais biologicamente (logo, materialmente, e registradas pelas características específicas de nossos sentidos) dadas. $\mathrm{O}$ espaço perceptivo se refere às maneiras pelas quais processamos neurologicamente a experiência física e biológica e a registramos no universo do pensamento. $\mathrm{O}$ espaço simbólico, por outro lado, é abstrato (e pode supor o desenvolvimento de uma linguagem abstrata como a geometria ou a construção de formas arquitetônicas ou pictóricas). O espaço simbólico gera significações particulares através de leituras e de interpretações. A questão das práticas estéticas aparece neste campo. Neste domínio, Langer (1953), por sua vez, distingue os espaços "real" e "virtual". Segundo a autora, este último consiste em um "espaço construído pelas formas, as cores, etc.", a fim de produzir as imagens e as ilusões intangíveis que constituem o coração de todas as práticas estéticas. A arquitetura, diz ela, "é uma arte plástica, e seu primeiro sucesso é sempre, inconsciente e inevitavelmente, uma ilusão: algo de puramente imaginário ou conceitual traduzido nas impressões visuais". Aquilo que existe no espaço real pode ser descrito facilmente, mas a fim de compreender o afeto que acompanha a confrontação da obra de arte nós devemos explorar o universo muito diferente do espaço virtual. E este, diz ela, nos projeta sempre dentro de um domínio étnico particular. Esse é o tipo de ideias que eu primeiramente abordei em Social Justice and the City. 


\section{O aporte de Henri Lefebvre}

É a partir desta tradição do pensamento espacializado que Lefebvre (quase certamente inspirado em Cassirer) construiu sua própria divisão tripartite: o espaço material (o espaço da experiência e da percepção aberto ao toque físico a à sensação); a representação do espaço (o espaço como concebido e representado); e os espaços de representação (o espaço vivido das sensações, a imaginação, das emoções e significados incorporados no modo como vivemos o dia a dia) (LEFEBVRE, 1991[1974]).

Se me concentro em Lefebvre não é porque, como supõem muitos autores na teoria cultural e literária, Lefebvre concede o momento originário do qual deriva todo o pensamento relativo à produção do espaço (tal tese é manifestamente absurda), mas porque considero mais pertinente trabalhar com as categorias de Lefebvre do que com aquelas de Cassirer. $\mathrm{O}$ espaço material corresponde simplesmente para nós, humanos, ao mundo da interação tátil e sensual com a matéria, é o espaço da experiência. Os elementos, momentos e eventos deste mundo são constituídos da materialidade de algumas qualidades. A maneira pela qual representamos este mundo é outra coisa, mas ainda aqui nós não concebemos ou representamos o espaço de maneira arbitrária; nós procuramos as descrições apropriadas, se não exatas, das realidades materiais que nos circundam por meio de representações abstratas (palavras, gráficos, cartas, diagramas, imagens, etc.). Henri Lefebvre, como Walter Benjamin, insiste que nós não vivemos como átomos materiais flutuando ao redor de um mundo material; nós temos igualmente imaginações, medos, emoções, psicologias, desejos e sonhos (BENJAMIN, 1999). Estes espaços de representação são uma parte integrante de nosso modo de viver no mundo. Podemos igualmente procurar representar a maneira com que este espaço é emocionalmente, afetivamente, mas também materialmente vivido através de imagens poéticas, composições fotográficas, reconstruções artísticas. A estranha espaço-temporalidade de um sonho, de um desenho, de uma aspiração oculta, de uma lembrança perdida ou mesmo de uma sensação ou tremer de medo quando andamos em uma rua, pode ser representada através de obras de arte que, em última instância, têm sempre uma presença mundana no espaço e tempo absolutos. Leibniz, igualmente, colocou a questão da existência de mundos e de sonhos espaço-temporais alternativos como de interesse considerável.

É tentador, como no caso da primeira divisão tripartite dos termos espaciais que evocamos, considerar as três categorias de Lefebvre 
ordenadas hierarquicamente. Mas aí também parece mais apropriado conservar as três categorias em tensão dialética. A experiência física e material da ordem espacial e temporal é mediada, em um certo grau, pela maneira com que espaço e tempo são representados. O oceanógrafo/físico nadando entre as ondas pode experimentá-las de modo diferente do poeta enamorado de Walt Whitman ou do pianista que adora Debussy. Ler um livro sobre a Patagônia afetará a maneira como experimentaremos aquele espaço quando formos até lá, mesmo que uma dissonância cognitiva considerável possa se instalar entre as expectativas geradas pela escrita e o modo pelo qual a experiência é efetivamente sentida. Os espaços e os tempos da representação que nos envolvem e nos rodeiam na nossa vida cotidiana afetam tanto nossas experiências diretas quanto nossa interpretação e compreensão. Podemos nem mesmo notar as qualidades materiais dos agenciamentos espaciais incorporados na vida cotidiana, porque nós nos conformamos espontaneamente às rotinas. No entanto, através das rotinas materiais cotidianas nós compreendemos o funcionamento das representações espaciais e construímos espaços de representação para nós mesmos (por exemplo, o sentimento intuitivo de segurança em um bairro familiar ou por sentir-se "em casa"). Somente conseguimos notar quando algo aparece completamente fora do lugar. $\mathrm{O}$ que quero sugerir é que o que realmente importa é a relação dialética entre as categorias, mesmo que seja útil, com vistas ao entendimento, distinguir cada elemento como um momento separado da experiência do espaço e do tempo.

Este modo de pensar o espaço me ajuda a interpretar as obras de arte e a arquitetura. Uma pintura como "O grito", de Munch, é um objeto material, mas ele funciona como um estado psíquico (o espaço da representação ou espaço vivido de Lefebvre), e tenta, através de um conjunto preciso de códigos representacionais (a representação do espaço ou espaço concebido) adotar uma forma física (o espaço material da pintura relacionado à nossa experiência física efetiva) que nos diz alguma coisa sobre a maneira pela qual Munch vivia este espaço. Este dá a impressão de ter vivido um tipo de pesadelo horrível, o gênero de pesadelo do qual acordamos gritando. E conseguiu exprimir algo desse sentido através do objeto físico. Muitos artistas contemporâneos, utilizando multimídia e técnicas cinéticas, criam espaços experienciais nos quais muitos modos de experiência do espaço-tempo se combinam. Veja, por exemplo, como é descrita no catálogo a contribuição de Judith Barry para a Terceira Bienal de Arte Contemporânea de Berlim: 
No seu trabalho experimental, a vídeo-artista Judith Barry questiona sobre o uso, a construção e a interação complexa entre espaços público e privado, mídia, sociedade e gêneros. Os temas das suas instalações e de seus escritos teóricos se posicionam em um campo de observação que evoca a memória histórica, a comunicação de massa e a percepção. Em um intervalo que se situa entre o imaginário do espectador e a arquitetura gerada pelas mídias, ela criou espaços imaginários, retratos alienados da realidade profana ... Na obra intitulada Voice Off ... o espectador penetra na estreiteza claustrofóbica do espaço de exibição, se aprofunda na obra e, forçado a mover-se pela instalação, prova impressões não somente cinéticas, mas cinestésicas. $\mathrm{O}$ espaço de projeção dividido oferece a possibilidade de entrar em contato com vozes diferentes. O uso e a escuta da voz como elemento principal, e a intensidade da tensão psíquica especialmente do lado masculino da projeção - evoca a força deste objeto intangível e efêmero. As vozes demonstram aos espectadores o modo pelo qual é possível mudar através delas, como procuramos controlá-las e a perda que sentimos quando não as ouvimos mais.

O catálogo conclui que Berry "põe em cena espaços de trânsito que deixam irresoluta a ambivalência entre sedução e reflexão" (Terceira Bienal de Arte Contemporânea de Berlim, 2004:48-49).

Mas para compreender plenamente a descrição do trabalho de Barry, é conveniente aportar os conceitos de espaço e de espaço-tempo a um nível de complexidade superior. Muitos elementos desta descrição não correspondem às categorias lefebvreanas, mas se referem mais às distinções entre espaço e tempo absolutos (a rígida estrutura física da exposição), espaço-tempo relativo (o movimento sequencial do visitante através do espaço) e espaço-tempo relacional (as lembranças, as vozes, a tensão psíquica, o intangível e o caráter efêmero, bem como a claustrofobia). Nós não podemos, contudo, abandonar as categorias lefebvreanas. Os espaços construídos possuem dimensões materiais, concebidas e vividas.

Proponho, por isso, efetuar um salto especulativo e colocar a divisão tripartite entre o espaço-tempo absoluto, relativo e relacional em relação com a divisão tripartite entre espaço experimentado, conceitualizado e vivido, identificados por Lefebvre. O resultado é uma matriz (de três linhas 
e três colunas) cujos pontos de interseção remetem a diferentes modalidades de compreensão dos significados do espaço e do espaçotempo. Poder-se-ia objetar, com justiça, que estou aqui restringindo possibilidades porque um modo de representação matricial está autoconfinado a um espaço absoluto. Esta é uma objeção perfeitamente válida. À medida que me engajo em uma prática representacional (conceitualização), não posso fazer justiça às dimensões experimentadas ou vividas da espacialidade. Por definição, portanto, a matriz que eu estabeleço e o modo como posso usá-la tem um poder revelador limitado. Mas com tudo isso esclarecido, penso ser útil considerar as combinações que surgem das diferentes interseções da matriz. A virtude da representação no espaço absoluto é que ela permite identificar os fenômenos com uma grande clareza. E com um pouco de imaginação, é possível refletir dialeticamente através dos elementos da matriz, de modo que cada momento é imaginado com uma relação interna a todas as outras. Proponho ilustrar o que tenho em mente (de algum modo condensado, arbitrário e esquemático) na figura 1. As entradas da matriz têm um caráter muito mais sugestivo que definitivo (os leitores poderão querer construir suas próprias entradas para atingir algum sentido da significação que proponho).

\begin{tabular}{|l|l|l|l|}
\hline & $\begin{array}{c}\text { Espaço material } \\
\text { (espaço } \\
\text { experimentado) }\end{array}$ & $\begin{array}{l}\text { Representações do } \\
\text { espaço (conceitualizado) }\end{array}$ & $\begin{array}{l}\text { Espaços de } \\
\text { representação } \\
\text { (espaço vivido) }\end{array}$ \\
\hline $\begin{array}{l}\text { Espaço } \\
\text { absoluto }\end{array}$ & $\begin{array}{l}\text { Muros, pontes, } \\
\text { portas, solo, teto, } \\
\text { ruas, edifícios, } \\
\text { cidades, montanhas, } \\
\text { continentes, } \\
\text { extensões de água, } \\
\text { marcadores } \\
\text { territoriais, fronteiras } \\
\text { e barreiras físicas, } \\
\text { condomínios } \\
\text { fechados }\end{array}$ & $\begin{array}{l}\text { Mapas cadastrais e } \\
\text { administrativos; geometria } \\
\text { euclidiana; descrição de } \\
\text { paisagem; metáforas do } \\
\text { confinamento, espaço } \\
\text { aberto, localização, arranjo } \\
\text { e posição (comando e } \\
\text { controle relativamente } \\
\text { fáceis) - Newton e } \\
\text { Descartes }\end{array}$ & $\begin{array}{l}\text { Sentimentos de } \\
\text { satisfação em torno } \\
\text { do círculo familiar; } \\
\text { sentimento de } \\
\text { segurança ou } \\
\text { encerramento devido } \\
\text { a confinamento; } \\
\text { sentimento de poder } \\
\text { conferido pela } \\
\text { propriedade, comando } \\
\text { e dominação sobre o } \\
\text { espaço; medo de } \\
\text { outros que "não são } \\
\text { dali". }\end{array}$ \\
\hline
\end{tabular}




\begin{tabular}{|c|c|c|c|}
\hline $\begin{array}{l}\text { Espaço (tempo) } \\
\text { relativo }\end{array}$ & $\begin{array}{l}\text { Circulação e fluxo de } \\
\text { energia, água, ar, } \\
\text { mercadorias, povos, } \\
\text { informação, dinheiro, } \\
\text { capital; acelerações } \\
\text { e diminuições na } \\
\text { friç̧ão da distância. }\end{array}$ & $\begin{array}{l}\text { Cartas temáticas e } \\
\text { topológicas (ex: o } \\
\text { sistema de metrô de } \\
\text { Londres); geometrias } \\
\text { e topologias não } \\
\text { euclidianas; } \\
\text { desenhos de } \\
\text { perspectiva; } \\
\text { metáforas de saberes } \\
\text { localizados, de } \\
\text { movimento, } \\
\text { mobilidade, } \\
\text { deslocamento, } \\
\text { aceleração, } \\
\text { distanciamento e } \\
\text { compressão do } \\
\text { espaço-tempo } \\
\text { (comando e controle } \\
\text { difíceis requerendo } \\
\text { técnicas } \\
\text { sofisticadas). Einstein } \\
\text { e Riemann }\end{array}$ & $\begin{array}{l}\text { Ansiedade por } \\
\text { não chegar na } \\
\text { aula no horário; } \\
\text { atração pela } \\
\text { experiência do } \\
\text { desconhecido; } \\
\text { frustração num } \\
\text { engarrafamento; } \\
\text { tensões ou } \\
\text { divertimentos } \\
\text { resultantes da } \\
\text { compressão } \\
\text { espaço-tempo, } \\
\text { da velocidade, } \\
\text { do movimento. }\end{array}$ \\
\hline $\begin{array}{l}\text { Espaço (tempo) } \\
\text { relacional }\end{array}$ & $\begin{array}{l}\text { Fluxos e campos de } \\
\text { energia } \\
\text { eletromagnética; } \\
\text { relações sociais; } \\
\text { superfícies } \\
\text { econômicas e de } \\
\text { renda potenciais; } \\
\text { concentrações de } \\
\text { poluição; potenciais } \\
\text { de energia; sons, } \\
\text { odores e sensações } \\
\text { trazidas pelo vento. }\end{array}$ & $\begin{array}{l}\text { Surrealismo; } \\
\text { existencialismo; } \\
\text { psicogeografias; } \\
\text { ciberespaço; } \\
\text { metáforas de } \\
\text { incorporação de } \\
\text { forças e de poderes } \\
\text { (comando e controle } \\
\text { muito difíceis - teoria } \\
\text { do caos, dialética, } \\
\text { relações internas, } \\
\text { matemáticas } \\
\text { quânticas) - Leibniz, } \\
\text { Whitehead, Deleuze, } \\
\text { Benjamin. }\end{array}$ & $\begin{array}{l}\text { Visões, } \\
\text { fantasmas, } \\
\text { desejos, } \\
\text { frustrações, } \\
\text { lembranças, } \\
\text { sonhos, } \\
\text { fantasmas, } \\
\text { estados } \\
\text { psíquicos (ex: } \\
\text { agorafobia, } \\
\text { vertigem, } \\
\text { claustrofobia) }\end{array}$ \\
\hline
\end{tabular}

Figura 1. Uma matriz dos possíveis significados do espaço como palavra-chave 


\section{Entre história e memória}

Parece-me interessante ler as categorias da matriz vertical e horizontalmente, e imaginar cenários de combinações complexas. Imaginem, por exemplo, o espaço absoluto de um condomínio fechado [gated community] emergente na costa de Nova Jersey. Alguns de seus habitantes se movem no espaço relativo diariamente, ao entrar ou sair do distrito financeiro de Manhattan, onde se inserem no movimento dos fluxos de crédito e de investimentos que afetam a vida social por todo o planeta. Eles adquirem assim um poder financeiro que lhes permite trazer de volta para o espaço absoluto de sua comunidade toda a energia, o exotismo alimentar e as mercadorias maravilhosas necessárias a seu estilo de vida privilegiado. Contudo, os habitantes se sentem vagamente ameaçados, porque percebem que existe no mundo um ódio visceral, indefinível e impossível de localizar, para com tudo o que é americano esse ódio se chama "terrorismo". Eles apoiam então um governo que promete protegê-los dessa ameaça nebulosa. Mas, ao mesmo tempo, tornam-se a cada dia mais paranoicos diante da hostilidade percebida no mundo que os rodeia, e procuram reforçar seu espaço absoluto para se proteger, construindo muros mais e mais altos e contratando vigilantes armados para proteger suas fronteiras. Enquanto isso, o consumo descontrolado de energia para fazer funcionar seus veículos blindados que os levam à cidade todo dia acrescenta uma gota que faz transbordar o copo em relação ao clima global. Os padrões de circulação atmosférica mudam dramaticamente. Então, conforme o sedutor mas impreciso imaginário popular da teoria do caos, uma borboleta bate as asas em Hong Kong, desencadeia um ciclone devastador que atinge a costa de Nova Jersey e varre esse condomínio fechado do mapa. Muitos de seus residentes morrem porque têm tanto medo do mundo exterior que não escutam as mensagens de alarme que os convidam a evacuar a área. Se se tratasse de uma produção hollywoodiana, um cientista solitário perceberia o perigo e salvaria a mulher que ama, que até então o ignorava, mas que agora, agradecida, cai de amores por ele...

Ao se contar uma história simples como esta, percebe-se que é impossível confinar-se em apenas uma modalidade de pensamento espacial e espaço-temporal. As ações empreendidas no espaço absoluto só fazem sentido em termos relacionais. Ainda mais interessantes, portanto, são as situações em que momentos na matriz estão em uma tensão dialética mais explícita. Deixe-me ilustrar. 
Quais princípios espaciais e espaço-temporais devem ser mobilizados para se redesenhar o lugar conhecido como "Marco Zero" em Manhattan? Trata-se de um espaço absoluto que pode ser reconstruído materialmente e, para este fim, cálculos de engenharia (informados pela mecânica newtoniana) e projetos de arquitetura precisam ser feitos. Há inúmeras discussões sobre muros de contenção e a capacidade do local de suportar grandes transformações. Julgamentos estéticos sobre a maneira como o espaço, uma vez transformado em um artefato material de certo tipo, pode ser vivido, bem como concebido e experimentado, tornam-se igualmente importantes (Kant aprovaria). O problema é organizar o espaço físico a fim de produzir um efeito emocional e, ao mesmo tempo, compatibilizá-lo com certas expectativas (tanto comerciais quanto emocionais e estéticas) sobre como o espaço poderia ser vivido. Uma vez construída, a experiência do espaço poderia ser mediada pelas formas representacionais (como os guias e planos) que nos ajudam a interpretar os significados pretendidos do lugar assim reconstruído. Mas mover-se dialeticamente apenas através da dimensão do espaço absoluto é muito menos recompensador do que os insights produzidos ao se recorrer a outros enquadramentos espaçotemporais. Os investidores imobiliários capitalistas estão plenamente conscientes da localização relativa do sítio e julgam suas perspectivas de desenvolvimento comercial de acordo com uma lógica de relações de troca. Sua centralidade e proximidade em relação às funções de comando e de controle de Wall Street são atributos importantes, e se o acesso aos meios de transporte puder ser melhorado ao longo do processo de reconstrução, melhor ainda, já que isso acrescentaria valor ao terreno e à propriedade. Para os investidores, o sítio não existe meramente no interior do espaçotempo relativo: a sua reestruturação oferece perspectivas de transformação do espaço-tempo relativo, assim como perspectivas de elevação do valor comercial dos espaços absolutos (através de melhorias no acesso a aeroportos, por exemplo). O horizonte temporal seria dominado por considerações relativas à taxa de amortização e à taxa de interesse/desconto aplicada aos investimentos de capital fixo no ambiente construído.

Porém, haveria muito provavelmente objeções por parte da população, lideradas pelas famílias daqueles que morreram naquele local, para pensar-se e construir-se apenas com base em lógicas socioespaciais absolutas ou relativas. Seja o que for que construírem ali, o edifício tem de dizer algo sobre sua história e sua memória. Haverá também provavelmente pressões para que se diga algo sobre os significados de comunidade e de nação, bem como sobre possibilidades futuras (talvez 
mesmo a perspectiva de verdades eternas). Tampouco se poderia mais ignorar a questão de sua conectividade espacial e relacional com o resto do mundo. Até mesmo os investidores capitalistas não seriam avessos a uma combinação de seus interesses comerciais mundanos com os relatos mais simbólicos e inspiradores (que enfatizam o poder e a indestrutibilidade do sistema político-econômico do capitalismo global que recebeu tamanho golpe em 11/9) ao erigir, por exemplo, um imponente símbolo fálico provocador. Eles também buscam um poder expressivo no espaço-tempo relacional. Mas há todo tipo de relacionalidades a explorar. O que saberemos sobre aqueles que atacaram e até onde vamos estabelecer conexões? O sítio é - e terá - uma presença relacional no mundo, independentemente do que ali for construído, e é importante refletir sobre como essa presença funciona: será vivenciada como um símbolo da arrogância dos EUA ou como um signo de compaixão e compreensão global? Considerar tais questões requer que abracemos uma concepção relacional do espaço-tempo.

Se, como se referiu Benjamin, história (um conceito temporal relativo) não é o mesmo que memória (um conceito temporal relacional), então temos uma escolha entre historicizar os eventos do 11 de Setembro ou tentar submetê-los a um trabalho de memória. Se o lugar é meramente historicizado no espaço relativo (por um certo tipo de monumentalidade) então isso impõe uma narrativa fixa no espaço. O efeito será o encerramento de futuras possibilidades e interpretações. Tal fechamento tenderá a estreitar a potência geradora que permitiria construir um futuro diferente. Por outro lado, memória é, segundo Walter Benjamin, uma potencialidade que às vezes pode "brilhar" incontrolavelmente em momentos de crise para revelar novas possibilidades (BENJAMIN, 1968). $\mathrm{O}$ modo como o local poderia ser vivido por aqueles que o encontram se torna então imprevisível e incerto. A memória coletiva, um difuso, mas poderoso sentido que tanto permeia uma cena urbana, pode desempenhar um papel significativo na animação dos movimentos políticos e sociais. $\mathrm{O}$ Marco Zero não pode ser outra coisa que não um lugar de memória coletiva, e o problema dos arquitetos é traduzir esta sensibilidade difusa em um espaço absoluto de tijolos, cimento, aço e vidro. E se, como Balzac uma vez colocou, "a esperança é uma memória que deseja", então a criação de um "espaço de esperança" naquele lugar requer que a memória seja internalizada, ao mesmo tempo em que caminhos são deixados abertos para a expressão do desejo (HARVEY, 2003: cap. 1). 
A expressiva relacionalidade do Marco Zero em si mesma levanta questões fascinantes. As forças que convergiram no espaço para produzir o 11 de Setembro foram complexas. Como, então, podemos considerar essas forças? É possível que algo experienciado como uma tragédia pessoal e local possa ser reconciliado com uma compreensão de forças internacionais que foram tão poderosamente condensadas naqueles poucos momentos de fragilidade, em um lugar particular? Conseguiremos perceber neste espaço o ressentimento generalizado a respeito da hegemonia estadunidense e da maneira egoísta com que ela se exerceu durante as décadas de 1980 e 1990? Conseguiremos saber que a administração Reagan desempenhou um papel chave na criação e apoio aos talibãs no Afeganistão a fim de minar a ocupação soviética, e que Osama bin Laden passou de aliado dos EUA a inimigo, em razão do apoio estadunidense ao regime corrupto da Arábia Saudita? Ou aprenderemos apenas sobre "outros" covardes, estrangeiros e portadores do mal que odiaram os EUA e tentaram destruí-lo em razão de que tudo o que esta nação sustenta em nome da liberdade? A espaçotemporalidade relacional do evento e do local pode ser exumada com algum esforço de escavação. Mas a maneira de representá-la e de materializá-la é incerta. O resultado dependerá claramente de lutas políticas. $\mathrm{E}$ as batalhas mais violentas se travarão em torno do que a reconstrução do espaço-tempo relacional irá invocar. Esse foi o tipo de questões que encontrei quando tentei interpretar o significado da basílica de Sacré-Coeur em Paris tendo como pano de fundo a memória histórica da Comuna de Paris.

Isso me leva a fazer algumas observações sobre a dimensão política do argumento. Pensar as diferentes maneiras como espaço e espaço-tempo são usados como palavra-chave nos ajuda a definir certas condições de possibilidade para o engajamento crítico. Isso também nos abre caminhos para identificarmos reivindicações contraditórias e possibilidades políticas alternativas, além de nos incitar a considerar a maneira como moldamos fisicamente nosso meio e o modo como o representamos e o vivemos. Creio ser justo dizer que a tradição marxista não tem sido suficientemente engajada em questões deste tipo, e que essa falha geral (apesar de existirem, é claro, numerosas exceções) tem frequentemente significado a perda de oportunidades para certos tipos de políticas transformadoras. Se, por exemplo, a arte realista socialista falha ao capturar a imaginação e se a monumentalidade alcançada sob os regimes comunistas do passado era tão pobre em inspiração, se comunidades planejadas e cidades comunistas geralmente parecem tão mortas para o mundo, uma forma de se pensar criticamente sobre tais questões seria então o de voltar o olhar para as 
formas de se pensar sobre espaço e espaço-tempo e os papeis não necessariamente limitadores e constringentes que tais perspectivas desempenharam nas práticas de planejamento socialistas.

\section{O espaço na tradição marxista}

Não tem havido muitos debates explícitos sobre tais questões no âmbito da tradição marxista, ainda que o próprio Marx fosse um pensador relacional. Em situações revolucionárias como as de 1848, Marx se preocupou com o fato de que o passado poderia ser um pesadelo no cérebro dos vivos, e imediatamente colocou a questão sobre como uma poesia revolucionária do futuro poderia ser construída naquele momento (MARX, 1963). Na época, Marx também suplicou para que Cabet não levasse seus seguidores comunistas para o novo mundo. Para Marx os Icarianos iriam ali apenas reproduzir as atitudes e crenças interiorizadas da experiência do velho mundo. Marx aconselhava que eles deveriam permanecer na Europa como bons comunistas e lutar pela transformação revolucionária naquele espaço, mesmo que houvesse o risco de uma revolução realizada "no nosso pequeno canto do mundo" ser vítima de forças globais circundantes (citado em MARIN, 1984).

Lênin, claramente angustiado pelo modo de apresentação idealista de Mach, procurou reforçar as concepções absolutas e mecanicistas de espaço e tempo associadas a Newton como a única base materialista possível para a investigação científica. Ele o fez ao mesmo tempo em que Einstein colocava em evidência concepções relativas, mas igualmente materialistas, do espaço. A visão estrita de Lênin foi, em algum grau, atenuada pela virada de Lukács para uma perspectiva mais flexível da história e da temporalidade. Mas a perspectiva construtivista de Lukács na relação com a natureza foi categoricamente rejeitada pela afirmação de Wittfogel de um materialismo nu e cru que assumiu as características de um determinismo ambiental. Por outro lado, nos trabalhos de Thompson, Williams e outros encontramos diferentes níveis de apreciação, particularmente da dimensão temporal, embora espaço e lugar estejam também onipresentes. No romance de Raymond Williams, People of the Black Mountains, a relacionalidade do espaço-tempo é central. Williams a utiliza para dar uma coerência à narrativa, e enfatiza as diferentes formas de conhecimento que acompanham os diferentes sentidos de espaço-tempo 
Se vidas e lugares vinham sendo seriamente buscados, uma poderosa ligação a vidas e lugares era plenamente demandada. $\mathrm{O}$ modelo do poliestireno e seus equivalentes textuais e teóricos mantiveram-se diferentes da substância que reconstruíram e simularam... Em seus livros e mapas na biblioteca ou na casa no vale, havia uma história comum que poderia ser transposta a qualquer lugar, em uma comunidade concebida em torno da busca de evidências e da racionalidade. Mas assim que ele se mudasse para a montanha, outro tipo de mentalidade se afirmava; obstinadamente nativo e local, apesar do alcance de um fluxo comum mais amplo, em que toque e respiração substituíam arquivo e análise; não história como narrativa mas histórias como vidas. (WILLIAMS, 1989:10-12)

Para Raymond Williams, a relacionalidade ganha vida à medida que se caminha para a montanha. Estabelece-se uma sensibilidade completamente diferente daquela construída a partir de arquivos. É interessante constatar que é apenas nos seus romances que Williams parece apto a entrar neste problema. No seio da tradição marxiana, à exceção de Lefebvre e dos geógrafos, falta uma compreensão mais vasta a respeito das problemáticas de espaço e tempo. Então, como tais perspectivas de espaço e espaço-tempo se tornam mais intimamente integradas em nossas leituras, interpretações e usos da teoria marxiana? Deixe-me colocar de lado todas as ressalvas preliminares e nuances para que possa apresentar um argumento em termos mais completos. 


\begin{tabular}{|l|l|l|l|}
\hline Espaço absoluto & $\begin{array}{l}\text { Espaço material } \\
\text { (da experiência) }\end{array}$ & $\begin{array}{l}\text { Representações do } \\
\text { espaço (espaço } \\
\text { concebido) }\end{array}$ & $\begin{array}{l}\text { Espaços de } \\
\text { representação } \\
\text { (espaço vivido) }\end{array}$ \\
\hline $\begin{array}{l}\text { Mercadorias úteis, } \\
\text { processo de } \\
\text { trabalho concreto, } \\
\text { notas e moedas } \\
\text { (dinheiro local?, } \\
\text { propriedade privada } \\
\text { Ifronteiras do } \\
\text { Estado, capital fixo, } \\
\text { usinas, ambientes } \\
\text { construídos, } \\
\text { espaços de } \\
\text { consumo, piquete } \\
\text { de greve, espaços } \\
\text { ocupados (sit-ins), } \\
\text { tomada da Bastilha } \\
\text { ou do Palácio de } \\
\text { Inverno }\end{array}$ & $\begin{array}{l}\text { Valores de uso e } \\
\text { trabalho concreto } \\
\text { Exploração no } \\
\text { processo de trabalho } \\
\text { (Marx) vs trabalho } \\
\text { como jogo criativo; } \\
\text { mapas de } \\
\text { propriedade privada e } \\
\text { de exclusões de } \\
\text { classe; mosaico de } \\
\text { desenvolvimentos } \\
\text { geográficos } \\
\text { desiguais. }\end{array}$ & $\begin{array}{l}\text { Alienação vs } \\
\text { satisfação criativa; } \\
\text { individualismo } \\
\text { isolado vs } \\
\text { solidariedades } \\
\text { sociais; lealdade ao } \\
\text { lugar, à classe, à } \\
\text { identidade, etc.; } \\
\text { privação relativa, } \\
\text { injustiça; falta de } \\
\text { dignidade; raiva vs } \\
\text { satisfação. }\end{array}$ \\
\hline
\end{tabular}




\begin{tabular}{|c|c|c|c|}
\hline $\begin{array}{l}\text { Espaço (tempo) } \\
\text { relativo }\end{array}$ & $\begin{array}{l}\text { Troca material, } \\
\text { comércio, circulação e } \\
\text { fluxo de mercadorias, } \\
\text { energia, força de } \\
\text { trabalho, dinheiro, } \\
\text { crédito ou capital, } \\
\text { percurso periferia- } \\
\text { centro da cidade e } \\
\text { migração, depreciação } \\
\text { e degradação, fluxo de } \\
\text { informação e agitação } \\
\text { do fora }\end{array}$ & $\begin{array}{l}\text { Valor de troca (valor } \\
\text { em movimento) } \\
\text { Esquemas de } \\
\text { acumulação; cadeias } \\
\text { de mercadorias; } \\
\text { modelos de migrações } \\
\text { e de diásporas, } \\
\text { modelos de input- } \\
\text { output, teorias de } \\
\text { "fixos" espaço- } \\
\text { temporais, aniquilação } \\
\text { do espaço pelo tempo, } \\
\text { circulação do capital } \\
\text { através do ambiente } \\
\text { construído; formação } \\
\text { do mercado mundial, } \\
\text { redes; relações } \\
\text { geopolíticas e } \\
\text { estratégias } \\
\text { revolucionárias }\end{array}$ & $\begin{array}{l}\text { Fetiche da } \\
\text { mercadoria e do } \\
\text { dinheiro (desejo } \\
\text { perpétuo } \\
\text { insatisfeito); } \\
\text { ansiedade / } \\
\text { euforia face à } \\
\text { compressão } \\
\text { espaço- } \\
\text { temporal; } \\
\text { instabilidade; } \\
\text { insegurança; } \\
\text { intensidade da } \\
\text { ação e do } \\
\text { movimento vs } \\
\text { repouso; "tudo o } \\
\text { que é solido } \\
\text { desmancha no } \\
\text { ar"... }\end{array}$ \\
\hline $\begin{array}{l}\text { Espaço (tempo) } \\
\text { relacional }\end{array}$ & $\begin{array}{l}\text { Processo de trabalho } \\
\text { abstrato, capital fictício; } \\
\text { movimentos de } \\
\text { resistência; } \\
\text { manifestações } \\
\text { repentinas e irrupções } \\
\text { expressivas de } \\
\text { movimentos políticos } \\
\text { (anti-guerra, 1968, } \\
\text { Seattle...), "o espírito } \\
\text { revolucionário } \\
\text { desperta" }\end{array}$ & $\begin{array}{l}\text { Valores-dinheiro } \\
\text { O valor como tempo de } \\
\text { trabalho socialmente } \\
\text { necessário; como } \\
\text { trabalho humano } \\
\text { objetivado em relação } \\
\text { com o mercado } \\
\text { mundial; as leis do } \\
\text { valor em movimento e } \\
\text { o poder social do } \\
\text { dinheiro (globalização); } \\
\text { esperanças e medos } \\
\text { revolucionários; } \\
\text { estratégias de } \\
\text { mudança }\end{array}$ & $\begin{array}{l}\text { Valores } \\
\text { Hegemonia } \\
\text { capitalista ("não } \\
\text { há alternativa"); } \\
\text { consciência } \\
\text { proletária; } \\
\text { solidariedades } \\
\text { internacionais, } \\
\text { direitos } \\
\text { universais; } \\
\text { sonhos } \\
\text { utópicos; } \\
\text { multidão; } \\
\text { empatia com os } \\
\text { outros; "um } \\
\text { outro mundo é } \\
\text { possível” }\end{array}$ \\
\hline
\end{tabular}

Figura 2. Matriz espaço-temporal para a teoria Marxiana 
No primeiro capítulo do Capital, Marx introduz três conceitos chave de valor de uso, valor de troca e valor. Tudo o que é valor de uso se inscreve no domínio do espaço e do tempo absolutos (figura 2). Trabalhadores individuais, máquinas, mercadorias, fábricas, estradas, casas, e processos de trabalho real, gastos de energia, etc., podem ser individualizados, descritos e compreendidos no âmbito do quadro newtoniano de espaço e tempo absolutos. Tudo o que se refere a valor de troca, por outro lado, inscreve-se em uma perspectiva de espaço-tempo relativo, porque a troca implica movimentos de mercadorias, de dinheiro, de capital, de força de trabalho e de pessoas através do tempo e do espaço. É a circulação, o movimento perpétuo, que importa. A troca, como observa Marx, derruba, portanto, todas as barreiras do espaço e do tempo. Ela remodela permanentemente as coordenadas em que vivemos nossas vidas cotidianas. Com o advento do dinheiro, esta mudança qualitativa radical definiu um universo ainda mais vasto e fluido de relações de troca através do espaço-tempo relativo do mercado mundial (compreendido não como uma coisa, mas como interação e movimento contínuos). A circulação e a acumulação do capital ocorrem no espaço-tempo relativo. O valor é, por sua vez, um conceito relacional. Sua referência é, portanto, o espaço-tempo relacional. Marx estabelece (às vezes surpreendentemente) que o valor é imaterial, mas objetivo. "Nenhum átomo de matéria entra na objetividade das mercadorias de valor". Em consequência, o valor "não possui um rótulo que descreva o que ele é", mas oculta seu caráter relacional no fetichismo da mercadoria (MARX, 1967:167). A única maneira de aproximação é via aquele mundo peculiar em que relações materiais são estabelecidas entre pessoas (nós nos relacionamos uns com os outros a partir do que produzimos e comercializamos), e entre as coisas (preços são definidos por aquilo que produzimos e trocamos). Valor é, em resumo, uma relação social. Como tal, é impossível medi-lo, exceto por meio de seus efeitos (tente mensurar qualquer relação social diretamente e você verá que o esforço é vão). $\mathrm{O}$ valor internaliza toda a geografia histórica de inumeráveis processos de trabalho condicionados por ou em relação à acumulação de capital no espaço tempo do mercado mundial. Muitos se surpreendem ao descobrir que o conceito mais fundamental de Marx é "imaterial mas objetivo", dado o modo como Marx é geralmente retratado como um materialista para quem tudo o que é imaterial é abominável. Esta definição relacional de valor, noto de passagem, torna discutíveis, senão mal colocadas, todas as tentativas de dar-lhe uma medida direta e essencialista. As relações sociais não podem ser medidas senão por seus efeitos. 
Se minha caracterização das categorias marxianas está correta, nenhuma prioridade pode ser conferida a um dos quadros espaçotemporais. Os três quadros espaço-temporais devem ser mantidos em tensão dialética uns com os outros, da mesma maneira que o valor de uso, o valor de troca e o valor interagem dialeticamente na teoria marxiana. Não existiria, por exemplo, nenhum valor no espaço-tempo relacional sem trabalhos concretos construídos em inumeráveis lugares no espaço e tempo absolutos. Nem o valor emergiria como um "poder imaterial mas objetivo" sem os inumeráveis atos de troca, os processos de circulação contínuos que mantêm o conjunto do mercado mundial no espaço-tempo relativo. $\mathrm{O}$ valor é, portanto, uma relação social que internaliza toda a história e a geografia do trabalho concreto no mercado mundial; expressa as relações sociais (principalmente, mas não exclusivamente, de classe) construídas pelo capitalismo na escala mundial. É crucial ressaltar a temporalidade envolvida, não apenas em razão do significado do trabalho 'morto' passado (o capital fixo inclui tudo o que está inscrito no ambiente construído), mas também por causa de todos os vestígios da história da proletarização, da acumulação primitiva, do desenvolvimento tecnológico que são incorporados na forma valor. Devemos reconhecer sobretudo os "elementos morais e históricos" que sempre entram na determinação do valor da força de trabalho (MARX, 1976: 275). Vemos, portanto, a teoria de Marx funcionar de maneira particular. O tecelão injeta valor (ex: o trabalho abstrato como determinação relacional) ao tecido ao realizar o trabalho concreto no espaço e tempo absolutos. A força objetiva da relação de valor é registrada quando o tecelão é forçado a desistir de fazer o tecido e a fábrica quebra porque as condições no mercado mundial são tais que tornam sem valor esta atividade neste espaço e tempo absolutos particulares. Enquanto tudo isto pode parecer óbvio, a falha em reconhecer a interação entre os diferentes quadros espaço-temporais na teoria marxiana produz uma confusão conceitual. Muita discussão sobre as assim chamadas "relações local-global" têm se tornado uma desordem conceitual, por exemplo, devido à inabilidade para se compreender as diferentes espaço-temporalidades envolvidas. Não podemos dizer que a relação de valor provoca o fechamento da fábrica como se se tratasse de uma força externa abstrata. São as mudanças concretas das condições de trabalho na China, quando mediadas através de processos de troca no espaço-tempo relativo, que transformam o valor como relação social de tal forma que levam o processo de trabalho concreto no México ao fechamento.

Até aqui, conferi atenção especial a uma leitura dialética da teoria marxiana ao longo da coluna esquerda da matriz. O que acontece quando, 
ao invés disso, eu começar a ler a matriz transversalmente? A materialidade do valor de uso e do trabalho concreto é bastante óbvia. Mas como isso pode ser representado e concebido? Descrições físicas são facilmente produzidas, mas Marx insiste que as relações sociais em que o trabalho é realizado são igualmente críticas. No regime capitalista, o trabalhador assalariado é concebido (segunda coluna) como um produtor de mais-valia para o capitalista, o que é representado como uma relação de exploração. Isto implica que o processo de trabalho é vivido (terceira coluna) como alienação. Em tipos diferentes de relações sociais (ex. aquelas do regime socialista), o trabalho poderia ser vivido como satisfação criativa e ser concebido como autorrealização pelo esforço coletivo. Não precisaria nem mesmo ser modificado materialmente para ser reconcebido e vivido de modo diferente. Essa era, afinal, a esperança de Lênin quando defendeu a adoção do fordismo nas fábricas soviéticas. Fourier, de sua parte, pensava que o trabalho deveria ser uma espécie de jogo e a expressão do desejo, e ser vivido como um contentamento sublime; para tanto, as qualidades materiais do processo de trabalho deveriam ser radicalmente reestruturadas. Neste ponto, devemos reconhecer a variedade de possibilidades concorrentes. Em seu livro Manufacturing Consent, por exemplo, Burawoy considerou que os trabalhadores da fábrica por ele estudada geralmente não vivenciavam o trabalho como alienação (BURAWOY, 1982). Isso acontecia porque os trabalhadores sufocavam a ideia da exploração ao tornar o local de trabalho um local para o desempenho de papéis e de jogos (no estilo de Fourier). O processo de trabalho era realizado pelos trabalhadores de tal forma que lhes permitia vivê-lo de modo não alienado. Existem algumas vantagens para o capital nesse processo, já que os trabalhadores "não alienados" geralmente trabalham de maneira mais eficaz. Os capitalistas têm então admitido certas medidas, como atividades aeróbicas, círculos de qualidade, etc., para tentar reduzir a alienação e enfatizar a incorporação. Eles produziram também concepções alternativas, que insistem sobre as recompensas do trabalho duro, além das ideologias que negam a teoria da exploração. Ainda que a teoria marxiana da exploração possa ser formalmente correta, ela nem sempre ou não necessariamente se traduz em alienação e resistência política. Depende muito da maneira como o processo é concebido. As consequências para a consciência política e a ação da classe trabalhadora são amplas. Parte da luta de classes consiste, portanto, em um trabalho de conscientização acerca do significado da exploração, assim como da concepção apropriada sobre como o trabalho concreto é concluído no âmbito das relações sociais capitalistas. Uma vez mais, é a tensão 
dialética entre o material, o concebido e vivido o que realmente importa. Se tratamos essas tensões de forma mecânica, estamos perdidos.

Embora o fato de refletir desta maneira seja útil, argumentei previamente que o "pensamento matricial" oferece oportunidades limitadas, a menos que estejamos preparados para circular livremente e dialeticamente através de todos os momentos da matriz simultaneamente. Deixe-me dar um exemplo. A forma primária da representação do valor é o dinheiro. Trata-se também de um conceito imaterial dotado de um poder objetivo, mas que deve igualmente adotar uma forma material como valor de uso. Isto é feito em primeira instância graças à emergência da mercadoria dinheiro (por exemplo, o ouro). Esta emergência ocorre, entretanto, através das trocas no espaço-tempo relativo, e são essas trocas que permitem que as formas tangíveis do dinheiro se tornem uma presença ativa no espaço e no tempo absolutos. Tal situação cria o paradoxo de que um valor de uso material particular (como o ouro ou o dólar) deve representar a universalidade do valor, do trabalho abstrato. Além disso, isso implica que o poder social pode ser apropriado por pessoas privadas e daí a real possibilidade de emergência do dinheiro como capital posto em circulação no espaço-tempo relativo. Há, como Marx aponta, antinomias, antíteses e contradições na maneira como o dinheiro é criado, concebido, colocado em circulação e utilizado tanto como um meio tangível de circulação quanto como uma representação de valor no mercado mundial. Precisamente porque o valor é imaterial e objetivo, o dinheiro combina sempre qualidades fictícias com formas tangíveis. Ele está sujeito a esta reversão que Marx descreve como fetichismo da mercadoria, de forma que relações materiais possam emergir entre pessoas, e relações sociais sejam registradas entre coisas. $\mathrm{O}$ dinheiro como objeto de desejo e como objeto de contemplação neurótica nos aprisiona em fetichismos, enquanto as contradições inerentes à forma dinheiro produzem inevitavelmente não apenas a possibilidade, mas também a inevitabilidade das crises capitalistas. As ansiedades relacionadas ao dinheiro estão frequentemente conosco e têm suas próprias localizações espaço-temporais (a criança pobre que para diante do vasto arsenal de mercadorias que estão perpetuamente fora de seu alcance na vitrine da loja). O espetáculo de consumo que invade a paisagem no espaço-tempo absoluto pode gerar sensações de privação relativa. Nós somos rodeados a todo o momento de manifestações do desejo fetichista de acessar o poder do dinheiro como representação de valor no mercado mundial. 
Para aqueles que não têm familiaridade com a teoria marxiana, tudo isso parecerá, sem dúvida, bastante misterioso. O principal, no entanto, é ilustrar como o trabalho teórico (e eu gostaria de sugerir que isso deveria ser válido para toda teoria social, literária e cultural) implica inevitável e necessariamente se mover minuciosa e dialeticamente através de todos os pontos da matriz, e além. Quanto mais circularmos, mais nossas análises serão profundas e de longo alcance. Não há caixas descontínuas e fechadas neste sistema. As tensões dialéticas não só não devem ser mantidas intactas. Elas devem ser continuamente expandidas.

\section{Conclusão}

Finalizo com algumas observações cautelosas. Nos anos recentes, muitos acadêmicos, e entre eles geógrafos, adotaram conceitos e modos de pensamento relacionais (apesar de não muito explícitos com relação àqueles de espaço-tempo). Este movimento, tão crucial quanto louvável, tem estado em alguma medida associado à virada cultural e pós-moderna. Mas do mesmo modo que a geografia tradicional e positivista limitou sua visão ao se concentrar exclusivamente sobre os aspectos absolutos e relativos, materiais e conceituais do espaço-tempo (abstendo-se do espaço vivido e relacional), há agora um sério perigo em apenas se deter ao relacional e ao vivido, como se o material e o absoluto não tivessem importância. Permanecer exclusivamente no canto inferior direito da matriz pode ser tão enganador, limitante e mistificador quanto se confinar a visão na parte superior esquerda. A única estratégia que realmente funciona é manter a tensão em movimento dialético através de todas as posições da matriz. Isto é o que nos permite melhor compreender como significados relacionais (como o de valor) são incorporados aos objetos, aos eventos e às práticas (como o processo de trabalho concreto) construídos no espaço e no tempo absolutos. Podemos ainda, a partir de outro exemplo, debater indefinidamente todos os tipos de ideias e projetos que expressam a relacionalidade do Ground Zero (Marco Zero), mas em algum momento algo precisa ser materializado no espaço e no tempo absolutos. Uma vez construído, o sítio adquire a "permanência" (o termo é de Whitehead) de uma forma física. E uma vez que o significado desta forma material está sempre aberto a novas concepções, de modo que as pessoas podem aprender a vivê-la de formas diferentes, a materialidade bruta da construção no espaço e no tempo tem seu próprio peso e sua autoridade. Da mesma forma, os movimentos políticos que aspiram a exercer algum 
poder no mundo permanecem ineficazes até que construam uma presença material. É muito bom e correto, por exemplo, evocar concepções relacionais como o proletariado em movimento ou a multidão em ascensão. Porém, ninguém sabe o que isto significa até o momento em que os corpos reais estejam nos espaços absolutos das ruas de Seattle, Québec e Genebra em um momento particular no tempo absoluto. Os direitos, como observa pertinentemente Don Mitchell, não significam nada sem a possibilidade de serem concretizados no espaço e no tempo absolutos:

Se o direito à cidade é um grito e uma exigência, então este grito só é escutado e esta exigência somente possui força se há um espaço a partir do qual e no qual este grito é audível e esta exigência, visível. No espaço público - na esquina das ruas ou nos parques, nas ruas ao longo dos tumultos e manifestações - as organizações políticas podem se representar para uma população mais ampla e essa representação confere aos gritos e demandas alguma força. Ao reivindicar o espaço público, ao criar espaços públicos, os grupos sociais tornam-se eles próprios públicos.

O espaço público, como Mitchell (2003:129-35) corretamente insiste, "é material" e "constitui um lugar de fato, um terreno sobre o qual e a partir do qual a atividade política emerge". É apenas quando a relacionalidade se conecta ao espaço e ao tempo absolutos da vida social e material que a política se torna viva. Negligenciar esta conectividade é condenar a política à irrelevância.

Compreender um pouco o sentido do que é o espaço e como as diferentes espacialidades e espaço-temporalidades funcionam é crucial para a construção de uma imaginação geográfica diferente. Mas o espaço revela-se uma palavra-chave extraordinariamente complicada. Ele funciona como uma palavra composta e possui múltiplas determinações, de modo que nenhum de seus significados pode ser propriamente compreendido de forma isolada. Mas é precisamente o que faz deste termo, em particular quando associado ao tempo, um termo tão rico em possibilidades. 


\section{O ESPAÇO COMO PALAVRA-CHAVE}

Resumo: Neste artigo David Harvey discute teoricamente "espaço" como uma palavra-chave, associando a visão tripartite espaço absoluto-relativorelacional com a leitura lefebvreana dos espaços percebido, concebido e vivido (também denominados espaços material ou experimentado, conceitualizado e da representação)

Palavras-chave: Espaço absoluto, relativo e relacional; espaço material, conceitualizado e vivido

\section{SPACE AS A KEYWORD}

Abstract: David Harvey in this article discuss theoretically "space" as a keyword, by associating the tripartite approach absolute-relative-relational space with Lefebvre's view of perceived, conceived and lived spaces (also called material or experienced space, conceptualized space and spaces of representation)

Keywords: Absolute, relative and relational space; material, conceptualized and lived space.

\section{BIBLIOGRAFIA}

BENJAMIN, W. 1999. The Arcades Project. Eiland, H. e McLaughlin, K. (org.) Cambridge, MA: Belknap Press.

1968. Illuminations. Nova York: Schocken.

BURAWOY, M. 1982. Manufacturing Consent: Changes in the Labor Process under Monopoly Capitalism. Chicago: University of Chicago Press. CASSIRER, E. 1994. An Essay on Man. New Haven: Yale University Press. DELEUZE, G. 1992. The Fold: Leibniz and the Baroque. Minneapolis: University of Minnesota Press.

FITZGERALD, J. 1979. Alfred North Whitehead's Early Philosophy of Space and Time. Nova York: Rowman e Littlefield.

HARVEY, D. 2003. Paris, Capital of Modernity. Nova York: Routledge. 
Blackwell

1996. Justice, Nature and the Geography of Difference. Londres:

. 1973. Social Justice and the City. Londres: Edward Arnold e Baltimore: John Hopkins University Press.

LANGER, S. 1953. Feeling and Form: A Theory of Art. Nova York: Prentice Hall.

MARIN, L. 1984. Utopics: A Spatial Play. Atlantic Heights: Humanities Press.

MARX, K. 1976. Capital vol.1. Nova York: Viking Press. , 1967 (1867). Capital vol. 1. Londres: Lawrence e Wishart.

. 1963. The Eighteenth Brumaire of Louis Bonaparte. Nova York: International Publishers.

MITCHELL, D. 2003, The right to the city: social justice and the fight for public space, New York: Guilford Press.

OSSERMAN, R. 1995. The Poetry of the Universe. Nova York: Doubleday.

TERCEIRA Bienal de Arte Contemporânea de Berlim. 2004. Catalogue:

Judith Barry, Voice Off. Berlim: Biennale.

WILLIAMS, R. 1989. People of the Black Mountains: the Beginnings. Londres: Chatto e Windus.

. 1985. Keywords: A Vocabulary of Culture and Society. Oxford:

Oxford University Press. 